\title{
Aplastic anemia in a patient with CVID due to NFKB1 haploinsufficiency
}

\author{
Tammarah Sklarz, ${ }^{1}$ Stephanie N. Hurwitz, ${ }^{2}$ Natasha L. Stanley, ${ }^{3,4,5}$ Jane Juusola, ${ }^{6}$ \\ Adam Bagg, ${ }^{2}$ and Daria Babushok ${ }^{4,5}$ \\ ${ }^{1}$ Cooper Medical School of Rowan University, Camden, New Jersey 08103, USA; ${ }^{2}$ Department of Pathology \\ and Laboratory Medicine, Hospital of the University of Pennsylvania, Philadelphia, Pennsylvania 19104, USA; \\ ${ }^{3}$ Philadelphia College of Osteopathic Medicine, Philadelphia, Pennsylvania 19131, USA; ${ }^{4}$ Division of \\ Hematology-Oncology, Department of Medicine, Hospital of the University of Pennsylvania, Philadelphia, \\ Pennsylvania 19104, USA; ${ }^{5}$ Comprehensive Bone Marrow Failure Center, Children's Hospital of Philadelphia, \\ Philadelphia, Pennsylvania 19104, USA; ${ }^{6}$ GeneDx, Gaithersburg, Maryland 20877, USA
}

Corresponding author: daria.babushok@pennmedicine upenn.edu

(C) 2020 Sklarz et al. This article is distributed under the terms of the Creative Commons Attribution-NonCommercial License, which permits reuse and redistribution, except for commercial purposes, provided that the original author and source are credited.

Ontology terms: aplastic anemia; bone marrow hypocellularity; defective production of NFKB1-dependent cytokines; immune dysregulation

Published by Cold Spring Harbor Laboratory Press

doi:10.1101/mcs.a005769
Abstract Acquired aplastic anemia (AA) is a life-threatening bone marrow failure caused by an autoimmune cytotoxic $T$ lymphocyte attack on hematopoietic stem and progenitor cells. Factors contributing to aberrant autoimmune activation in AA include a deficit of T regulatory cells and high levels of inflammatory cytokines. Several acquired conditions of immune dysregulation and genetic polymorphisms in inflammatory cytokines and human leukocyte antigen genes have been linked to an increased risk of AA. However, AA has not been reported in patients with Mendelian disorders of immune regulation. Here we report a patient with familial common variable immunodeficiency (CVID) caused by a pathogenic variant in NFKB1, who developed AA as an adult. The patient had a difficult clinical course and was unable to tolerate standard AA therapy with cyclosporine $A$ and eltrombopag, with complications attributed in part to the effect of cyclosporine A on NF-kB signaling. Our case suggests a novel link between genetic disorders of immune regulation and $A A$ and highlights the importance of recognizing inherited autoimmunity syndromes in AA patients for the selection of optimal therapy and prognostic counseling.

[Supplemental material is available for this article.]

\section{INTRODUCTION}

Acquired aplastic anemia (AA) is a rare life-threatening blood disease characterized pathologically by pancytopenia and a hypocellular bone marrow due to the immune-mediated destruction of early hematopoietic cells by cytotoxic T lymphocytes (Young 2018). Specific triggers of autoimmunity or the identities of autoantigens immunologically targeted in AA remain unknown. Several acquired conditions involving immune dysregulation have been linked to AA, such as Hodgkin lymphoma (Linaburg et al. 2019), immune checkpoint inhibitor therapy (Davis et al. 2019), thymoma (Gendron et al. 2020), autoimmune hepatitis (Brown et al. 1997), and eosinophilic fasciitis (de Masson et al. 2013). Additionally, a number of polymorphisms associated with overproduction of inflammatory cytokines (e.g., interferon- $\gamma$ [Dufour et al. 2004]) and certain human leukocyte antigen genes (Nakao et al. 1994; Babushok et al. 2017; Zaimoku et al. 2017) have been linked to an increased risk of AA. However, AA has not been previously reported in patients with inherited diseases of immune dysregulation. Here, we report a patient with common variable immune deficiency (CVID) caused by a pathogenic variant in the NF-kB1 gene (NFKB1), who developed AA during 
her adult life and clinically rapidly declined despite attempts at standard AA therapy. Our patient's case suggests a new connection between the immune dysregulation seen in primary immunodeficiencies and AA. Furthermore, we propose that alterations in NF-kB signaling as well as the more general complications associated with CVID, including liver dysfunction and enteropathy, may present unique challenges in the management of AA with currently available therapeutics.

\section{RESULTS}

\section{Clinical Presentation and Family History}

A 50-yr-old female was referred for an evaluation of suspected AA. Her past medical history was notable for CVID, which was diagnosed at the age of $12 \mathrm{yr}$, after having frequent upper respiratory infections as a child, and was managed with monthly intravenous immunoglobulin (IVIG). The patient's CVID-associated complications included a remote history of autoimmune hemolytic anemia, currently in remission, which was diagnosed in the patient's 20 s and was managed with a variety of immunosuppressants and splenectomy. In her 30s, the patient was diagnosed with Plummer-Vinson syndrome, a classical triad of iron deficiency, esophageal webs, and dysphagia, which has been associated with autoimmune disorders and carries an increased risk of squamous cell carcinoma of the oropharynx (Chisholm 1974; Messmann 2001). At the age of $38 \mathrm{yr}$, the patient developed a squamous cell carcinoma of the tongue, which was cured with surgical resection. She was subsequently well over the following 10 years, until 2 years prior to her current presentation when she developed anemia. Her initial evaluation was notable for a low reticulocyte count and a hypocellular marrow with an absence of erythroid precursors, consistent with acquired red cell aplasia. She was treated with corticosteroids and low-dose cyclosporine without response and eventually progressed to aplastic anemia.

The patient's family history was notable for Northern European and English ancestry, two healthy sisters who were monozygotic twins, a mother who died from glioblastoma at the age of $68 \mathrm{yr}$, and a maternal aunt with multiple sclerosis.

On physical exam, the patient was a thin middle-aged woman, weighing $106 \mathrm{lbs}$ at a height of $5^{\prime} 7^{\prime \prime}$. Physical exam was notable for a well-healed partial glossectomy without evidence of tongue carcinoma recurrence and no oral lesions or leukoplakia. Sclera were icteric. Cardiopulmonary exam was normal. There was no lymphadenopathy or hepatosplenomegaly. Skin exam showed no rashes, café-au-lait spots, or hypo- or hyperpigmented lesions. There was no nail dystrophy. Musculoskeletal exam was normal, with no thumb or radial anomalies.

Laboratory studies revealed a white blood cell count of $4 \times 10^{9}$ cells/L with a normal leukocyte differential, normocytic anemia (hemoglobin of $7 \mathrm{~g} / \mathrm{dL}$; mean corpuscular volume of $88 \mathrm{fL})$, a low reticulocyte count of $22 \times 10^{9}$ cells $/ \mathrm{L}$, and severe thrombocytopenia $\left(19 \times 10^{9}\right.$ platelets/L). A bone marrow biopsy revealed a severely hypocellular bone marrow with marked trilineage hypoplasia and scattered lymphohistiocytic aggregates, consistent with AA (Fig. 1). Cytogenetic examination of the bone marrow demonstrated a normal karyotype and targeted massively parallel sequencing of genes commonly mutated in hematologic malignancies showed no clinically significant variants. Consistent with an immunodominant antigen-driven autoimmune process in AA, polymerase chain reaction (PCR) analysis of the $T$-cell receptor gamma chain gene revealed a monoclonal rearrangement within a much more prominent polyclonal background (Risitano et al. 2004). There was no immunophenotypic evidence of clonal lymphoproliferative disorder or pan-T-cell antigen loss. Flow cytometry for paroxysmal nocturnal hemoglobinuria (PNH) revealed a subclinical (0.39\%) $\mathrm{PNH}$ clone in granulocytes. Extensive evaluation for alternative etiologies of the patient's bone 
COLD SPRING HARBOR Molecular Case Studies
Aplastic anemia in an NFKB1-mutated CVID patient

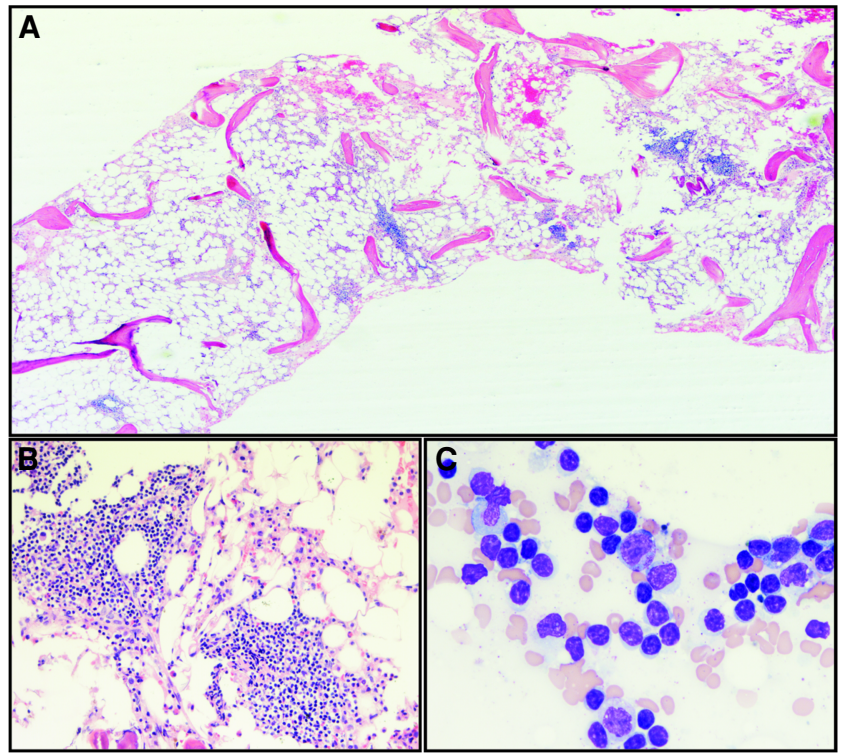

Figure 1. Bone marrow biopsy demonstrating hematopoietic trilineage hypoplasia. Hematoxylin and eosin (H\&E)-stained sections at (A) $5 \times$ and (B) $20 \times$ magnification illustrate a profoundly hypocellular marrow ( $5 \%-10 \%$ cellularity). Scattered interstitial lymphohistiocytic aggregates account for the majority of cellularity. (C) A concurrent bone marrow aspirate is hypocellular and composed predominantly of small lymphocytes and occasional left-shifted myeloid precursors, with virtually absent erythroid cells and megakaryocytes.

marrow failure, including underlying viral infection or nutritional deficiency was unrevealing (Supplemental Table S1). Chromosome breakage of the patient's peripheral blood lymphocytes in the presence of mitomycin $C$ and diepoxybutane was normal. Telomere testing showed low median lymphocyte telomere lengths between the first and fifth percentile for age in total lymphocytes as well as in the naive and memory T-cell and natural killer (NK)-cell subsets. The low telomere length was interpreted to likely reflect telomere attrition because of the underlying autoimmunity; however, to exclude an atypical telomeropathy or another occult inherited marrow failure syndrome, whole-exome sequencing was requested. Given the clinical urgency, the patient was started on treatment with cyclosporine and eltrombopag for a presumed diagnosis of $\mathrm{AA}$, while awaiting genetic testing results to determine more definitive therapy. An evaluation for allogeneic hematopoietic stem cell transplant was initiated. Unexpectedly, the patient was not able to tolerate cyclosporine at therapeutic doses, with an unusual degree of complications including progressive failure to thrive, $>10 \mathrm{lb}$ weight loss ( $10 \%$ body weight), fatigue, generalized pain and weakness, and septicemia within 2-3 wk of therapeutic cyclosporine dosing, requiring hospitalization. Cyclosporine was discontinued. Progressive liver dysfunction with rising hyperbilirubinemia and ascites precluded therapy with eltrombopag. Whole-exome sequencing revealed no disease-associated variants in genes associated with inherited bone marrow failure but identified a heterozygous variant in NFKB1 (Fig. 2; Table 1). Unfortunately, the patient continued to have a progressively deteriorating course and died within 4 mo of AA diagnosis from multiple complications, including recurrent neutropenic sepsis, severe malnutrition due to CVIDrelated enteropathy, and hepatic dysfunction.

\section{Variant Interpretation}

A constellation of a congenital immune deficiency, short lymphocyte telomere lengths, malnutrition, and progressive bone marrow failure was suspicious for an underlying inherited 
COLD SPRING HARBOR Molecular Case Studies

Aplastic anemia in an NFKB1-mutated CVID patient

A

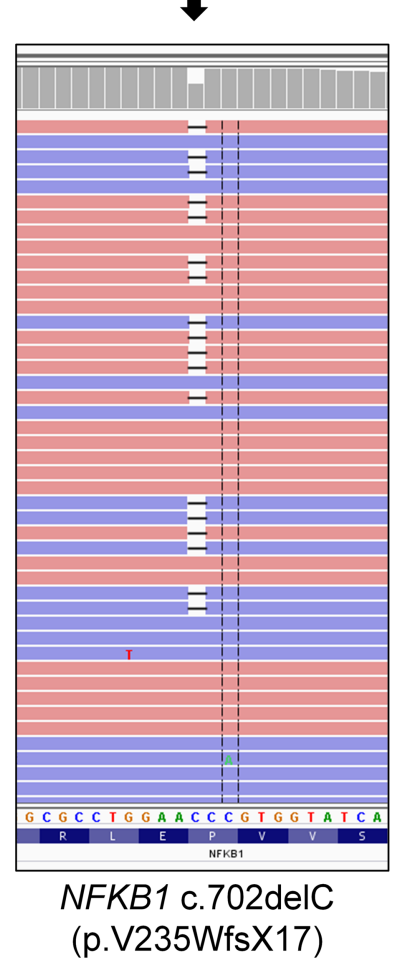

B

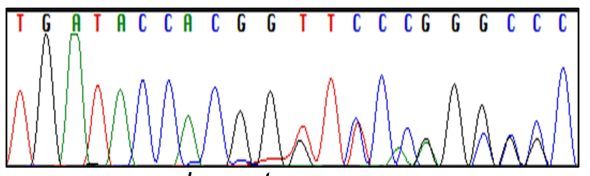

reverse complement

NFKB1 c.702delC (p.V235WfsX17)

Figure 2. The pathogenic variant in the NFKB1 gene (c.702delC; p.V235WfsX17) identified in a patient with CVID who developed AA as an adult. (A) Screenshot from Integrative Genome Viewer (IGV) showing a singlenucleotide deletion in the NFKB1 gene (c.702delC; black arrow). (B) Confirmatory Sanger sequencing demonstrating the region containing the frameshift mutation (black arrow; region is shown in reverse complement).

bone marrow failure syndrome. To screen the patient for an inherited etiology of her bone marrow failure, we performed whole-exome sequencing including sequencing of mitochondrial DNA. One heterozygous pathogenic variant in exon 8 of the NFKB1 gene (p.V235Wfs*17, c.702delC) was identified (Fig. 2). There were two additional variants in a gene associated with bone marrow failure and immunologic disorders (Supplemental Table S2); however, these were determined not to contribute to the patient's phenotype. Two variants in the DOCK8 gene, linked to autosomal recessive hyper IgE syndrome, were located in cis in the same allele and the patient lacked clinical features of hyper IgE syndrome with no eosinophilia, eczema, or recurrent viral infections. The identified pathogenic variant in NFKB1 is predicted to lead to NFKB1 haploinsufficiency because of protein truncation or nonsense-mediated mRNA decay. It has not been previously reported in association with CVID and has not been previously identified in population databases (Genomes

Table 1. Genomic findings

\begin{tabular}{cccccccc}
\hline Gene & Disease & Mode of inheritance & Variant & Coding DNA & Zygosity & Inherited from & Variant classification \\
\hline NFKB1 & $\begin{array}{c}\text { Common variable } \\
\text { immunodeficiency }\end{array}$ & Autosomal dominant & p.V235Wf*17 & c.702delC & Heterozygous & Unknown & Pathogenic \\
\hline
\end{tabular}


COLD SPRING HARBOR Molecular Case Studies
Aplastic anemia in an NFKB1-mutated CVID patient
Project Consortium et al. 2015; Lek et al. 2016; Exome Variant Server, Genome aggregation database [gnomAD]). Although germline status of the NFKB1 variant in our patient was not formally verified in paired nonhematopoietic tissue, NFKB1 is not a known cancer gene (Sondka et al. 2018), and NFKB1 mutations have not been described in age-related clonal hematopoiesis (Genovese et al. 2014; Jaiswal et al. 2014). The patient's clinical presentation (Table 2), together with a pathogenic heterozygous variant in NFKB1 detected in the patient's peripheral blood, is most consistent with autosomal dominant CVID caused by a germline NFKB1 variant. The patient's sisters (monozygotic twins) were negative for the variant, and the other family members were not tested. Given the family history of glioblastoma in the patient's mother and multiple sclerosis in the maternal aunt, two conditions linked to NF-кB dysregulation (Rajaraman et al. 2009; Mieczkowski et al. 2015; Cartwright et al. 2016; Kina et al. 2019; Zhou et al. 2020), the patient's NFKB1 variant could have been inherited from the maternal side of her family; alternatively, the variant may have emerged de novo.

\section{DISCUSSION}

In this report, we present a patient with familial NFKB1-associated CVID syndrome who developed AA in adulthood. Although CVID can be associated with a variety of autoimmune complications, including autoimmune cytopenias such as immune thrombocytopenia (ITP), hemolytic anemia, Evans syndrome, and autoimmune neutropenia (Podjasek and Abraham 2012), neither immune-mediated bone marrow failure nor AA have been previously reported. The patient was unable to tolerate standard AA therapies and rapidly declined. Our case highlights the importance of recognizing inherited syndromes of immune dysregulation such as CVID in AA patients, because of their unique complications and the potential implications for AA therapy, including the use of calcineurin inhibitors and timing and donor selection for hematopoietic stem cell transplantation.

CVID is the most common primary immunodeficiency caused by a failure of B-cell differentiation into functional plasma cells leading to immunoglobulin deficiency and recurrent sinopulmonary infections. Some CVID patients also have autoimmune and inflammatory manifestations (Table 1; Patuzzo et al. 2016; Lorenzini et al. 2020). In up to $20 \%$ of CVID patients, a genetic cause can be identified. Monoallelic loss-of-function mutations in NFKB1 are found in $4 \%$ of CVID patients and are the most common cause of familial CVID (Kaustio et al. 2017; Tuijnenburg et al. 2018; Lorenzini et al. 2020). NF-kB proteins are a family of five transcription factors (p50/p105, p52/p100, RelA, RelB, and c-Rel) characterized by a conserved DNA-binding domain (Rel homology domain). Dimers of NF- $\mathrm{kB}$ proteins direct transcriptional regulation of genes involved in various cellular processes including immune and inflammatory responses (Karin and Lin 2002; Lougaris et al. 2017). Intact NF-kB signaling contributes to proper B-cell maturation, survival, differentiation, and T-cell-independent antibody class switching (Vallabhapurapu and Karin 2009; Gerondakis and Siebenlist 2010; Kaileh and Sen 2012).

Although immune-mediated bone marrow failure has not been previously reported in CVID patients, the association of NFKB1-mutated CVID with other autoimmune disorders suggests that the cooccurrence of $A A$ and CVID in our patient was not coincidental. In fact, NFKB1 was previously found to have a critical role for maintaining a resting state of dendritic cells (DCs), induction of T-cell tolerance, and CD8 ${ }^{+}$lymphocyte cytotoxicity (Dissanayake et al. 2011). When pulsed with self-antigens, unstimulated DCs lacking NFKB1 may activate $\mathrm{CD}^{+} \mathrm{T}$ lymphocytes, leading to autoimmunity (Dissanayake et al. 2011). The absence of NFKB1 in resting antigen-presenting cells is associated with poor induction of $\mathrm{T}$-cell tolerance and higher granzyme B expression in cytotoxic $T$ cells, pointing to the role of dendritic cell defects in the establishment of autoimmunity in NKFB1-deficient 
Table 2. Clinical findings in autosomal dominant NFKB1 deficiency

\begin{tabular}{|c|c|}
\hline Clinical features & Patient \\
\hline Autosomal dominant inheritance & Yes \\
\hline \multicolumn{2}{|l|}{ Respiratory system } \\
\hline Upper respiratory tract infections (83.0\%) & Yes \\
\hline \multicolumn{2}{|l|}{ Pneumonia (59.0\%) } \\
\hline \multicolumn{2}{|l|}{ Bronchiectasis (25.6\%) } \\
\hline \multicolumn{2}{|c|}{ Granulomatous lymphocytic interstitial lung disease (GLILD) (7.4\%) } \\
\hline \multicolumn{2}{|c|}{ Gastrointestinal complications } \\
\hline \multicolumn{2}{|l|}{ Gastrointestinal infections (28.6\%) } \\
\hline Autoimmune enteropathy (13.9\%) & Yes \\
\hline \multicolumn{2}{|l|}{ Celiac-like disease (9.3\%) } \\
\hline \multicolumn{2}{|l|}{ IBD-like disease (5.6\%) } \\
\hline \multicolumn{2}{|l|}{ Diarrhea of unknown etiology (8.3\%) } \\
\hline \multicolumn{2}{|l|}{ Atrophic gastritis (4.6\%) } \\
\hline \multicolumn{2}{|l|}{ Liver } \\
\hline \multicolumn{2}{|l|}{ Hepatomegaly (24.7\%) } \\
\hline Liver disease (19.5\%) & Yes \\
\hline \multicolumn{2}{|l|}{ Malignancies (16.8\%) } \\
\hline \multicolumn{2}{|l|}{ Lymphoma (11.1\%) } \\
\hline Solid organ cancer (4.6\%) & Yes \\
\hline \multicolumn{2}{|l|}{ Spleen } \\
\hline \multicolumn{2}{|l|}{ Splenomegaly (48.5\%) } \\
\hline Splenectomy (11.9\%) & Yes \\
\hline \multicolumn{2}{|l|}{ Bone marrow } \\
\hline Antibody deficiency (88.9\%) & Yes \\
\hline Low lgA (87.4\%) & Yes \\
\hline Low lgG (74.4\%) & Yes \\
\hline Low IgM (70.9\%) & Yes \\
\hline Cytopenia (43.9\%) & Yes \\
\hline \multicolumn{2}{|l|}{ Novel clinical features } \\
\hline Acquired aplastic anemia & Yes \\
\hline \multicolumn{2}{|l|}{ Skin } \\
\hline \multicolumn{2}{|l|}{ Skin infections (37.7\%) } \\
\hline \multicolumn{2}{|l|}{ Rosacea } \\
\hline \multicolumn{2}{|l|}{ Autoimmune (14.9\%) } \\
\hline \multicolumn{2}{|l|}{ Psoriasis } \\
\hline \multicolumn{2}{|l|}{ Eczema } \\
\hline \multicolumn{2}{|l|}{ Necrotizing fasciitis } \\
\hline \multicolumn{2}{|l|}{ Alopecia } \\
\hline Thyroiditis (6.5\%) & \\
\hline Cardiovascular system & \\
\hline Cardiovascular complications (17.8\%) & \\
\hline Behçet disease (5.6\%) & \\
\hline Vasculitis (4.6\%) & \\
\hline
\end{tabular}




\begin{tabular}{ll}
\hline Table 2. (Continued) & Patient \\
\hline Clinical features & \\
\hline Bone/Joints & \\
Osteopenia (12.9\%) \\
Arthritis (10.3\%) \\
Enthesiopathy \\
Aphthous ulcerations (17.8\%) \\
Neurological complications (13.9\%) \\
Noninfectious fever (12.0\%) \\
Lymphoproliferation \\
Lymphadenopathy (35.3\%)
\end{tabular}

The summary of clinical features is adapted from Lorenzini et al. 2020.

patients (Dissanayake et al. 2011). Additionally, CVID patients were previously found to have lower numbers of $T$ regulatory cells, which may also contribute to the development of $A A$ (Fevang et al. 2007). Further studies are needed to better evaluate the role of NFKB1 and other genetic variants of immune regulation in the development of AA.

After the development of AA, our patient experienced rapid decline, further complicated by the difficulty in tolerating standard aplastic anemia therapy. Within days of starting therapeutic doses of cyclosporine, the patient experienced generalized failure to thrive, weight loss, hepatic dysfunction, and recurrent infections. The patient also recalled that during her previous treatment with low-dose cyclosporine, she also subjectively felt that "cyclosporine did not agree with her." Notably, cyclosporine is a potent inhibitor of Tcell activation and has multiple cellular functions, the best known of which is inhibition of calcineurin. Intracellular calcium release and its regulation by calcineurin were also found to be critical for NF-kB activation (Frantz et al. 1994; Steffan et al. 1995; Chan et al. 2013), and treatment with calcineurin inhibitors cyclosporine and tacrolimus has been shown to suppress NF-kB signaling (Venkataraman et al. 1995; Marienfeld et al. 1997; Meyer et al. 1997; Jin et al. 2015). We suspect that the use of cyclosporine in the context of NFKB1 haploinsufficiency may have led to enhanced toxicity as a result of further inhibition of NF-kB-dependent processes. Other CVID-related complications contributing to the poor outcome in our patient include recurrent infections, CVID enteropathy, and hepatic dysfunction.

In summary, in this report we expand the spectrum of hematologic complications of CVID to include AA and establish a novel link between genetic disorders of immune regulation and AA. Our case highlights potential challenges in managing AA in patients with CVID because of the underlying immune dysregulation, chronic complications of CVID, and what appears to be an epistatic interaction of calcineurin inhibitors in patients with genetic alterations of the NF-kB pathway. Increased recognition of immune-mediated bone marrow failure as a potential etiology of cytopenias in patients with CVID may improve outcomes by intervening at earlier stages of the disease and by anticipating potential complications. Allogeneic stem cell transplantation can be considered in selected patients; however, historical outcomes in CVID patients treated with bone marrow transplant have been poor, because of the high rates of treatment-refractory graft-versus-host disease and poor immune reconstitution leading to infectious complications (Wehr et al. 2015). Future studies are needed to determine optimal immunosuppressive therapies and transplant approaches in this difficult-to-treat patient population. 
COLD SPRING HARBOR Molecular Case Studies
Aplastic anemia in an NFKB1-mutated CVID patient

\section{METHODS}

\section{Patient Recruitment and Regulatory Approval}

The patient was enrolled into Penn-CHOP Bone Marrow Failure cohort, a bone marrow failure registry study approved by the Institutional Review Boards of Children's Hospital of Philadelphia and the University of Pennsylvania (IRB \# 10-007569). Informed consent from the patient was obtained in accordance with the Declaration of Helsinki. The diagnosis of aplastic anemia was established using standard criteria (International Agranulocytosis and Aplastic Anemia Study 1987; Wilson et al. 2014).

\section{Whole-Exome Sequencing}

Whole-exome sequencing was performed on patient's genomic DNA extracted from peripheral blood by paired-end massively parallel sequencing at the CLIA-approved commercial genetic testing laboratory (XomeDxPlus test, GeneDx). The exonic regions and flanking splice junctions were captured using a GeneDx proprietary system and sequenced at a mean depth of coverage of $158 \times$, with $98.7 \%$ of the captured regions covered by at least 10 sequence reads. Reads were aligned to human genome build GRCh37/UCSC hg19 and analyzed using a custom-developed analysis tool (XomeAnalyzer, GeneDx). Capillary sequencing was used to confirm all potentially reportable variants (Fig. 2).

\section{Hematopathology and Ancillary Studies}

Bone marrow histology was evaluated by a hematopathologist prior to the study enrollment. Cytogenetic analysis was performed by standard karyotyping techniques. Analysis of somatic mutations in genes associated with hematologic malignancies was performed at the University of Pennsylvania Center for Personalized Diagnostics as previously described (Fox et al. 2016), with the following 68 genes analyzed (ABL1, ASXL1, ATM, BCOR, BCORL1, BIRC3, BRAF, CALR, CBL, CDKN2A, CEBPA, CSF1R, CSF3R, DDX3X, DNMT3A, ETV6, EZH2, FAM5C, FBXW7, FLT3, GATA2, GNAS, HNRNPK, IDH1, IDH2, IL7R, JAK2, KIT, KLHL6, KRAS, MAP2K1, MAPK1, MIR142, MPL, MYC, MYCN, MYD88, NF1, NOTCH1, NOTCH2, NPM1, NRAS, PDGFRA, PHF6, POT1, PRPF4OB, PTEN, PTPN11, RAD21, RIT1, RUNX1, SETBP1, SF1, SF3A1, SF3B1, SMC1A, SRSF2, STAG2, TBL1XR1, TET2, TP53, TPMT, U2AF1, U2AF2, WT1, XPO1, ZMYM3, ZRSR2). TRG gene rearrangements were analyzed by PCR-based amplification using consensus $V$ and $J$ primers and capillary electrophoresis at the Penn Molecular Diagnostics Laboratory.

\section{Telomere Length Measurement and Chromosome Breakage Testing}

Flow-FISH telomere length measurements were performed on the lymphocyte subsets total lymphocytes, CD45RA positive naive T cells, CD45RA negative memory T cells, and CD57 positive NK cells at the CLIA-certified clinical telomere length testing center (Repeat Diagnostics, Inc.). Chromosome breakage testing in the presence or absence of mitomycin $\mathrm{C}$ and diepoxybutane with appropriate controls was performed on patient's lymphocytes at the Comprehensive Center for Fanconi Anemia.

\section{ADDITIONAL INFORMATION}

\section{Data Deposition and Access}

The patient's NFKB1 variant NM_003998.4(NFKB1):c.702del (p.Val235fs) was deposited to ClinVar (https://www.ncbi.nlm.nih.gov/clinvar/) under the accession number VCV00045 0428.2, variation ID: 450428. Patient consent was not granted to deposit WES data. 
Competing Interest Statement

The authors have declared no competing interest.

Received July 23, 2020; accepted in revised form September 4, 2020.

\section{Ethics Statement}

The patient was enrolled into the Penn-CHOP Bone Marrow Failure cohort, a bone marrow failure registry study approved by the Institutional Review Boards of Children's Hospital of Philadelphia and the University of Pennsylvania (IRB \# 10-007569). Informed consent from the patient was obtained in accordance with the Declaration of Helsinki.

\section{Acknowledgments}

The authors thank the patient for participation in this study and Dr. Monica Bessler and members of the Penn-CHOP Bone Marrow Failure Center for critical discussions.

\section{Author Contributions}

T.S. and D.B. performed the clinical review, analyzed the literature, and wrote and edited the manuscript. J.J. performed genetic sequencing analysis. S.N.H. and A.B. reviewed histopathology and ancillary studies. N.L.S. performed clinical chart review and prepared laboratory data tables. All authors revised the manuscript and are in agreement with the final version of the manuscript.

\section{Funding}

This work was supported by the National Heart, Lung, and Blood Institute (K08 HL132101) to D.B.

\section{REFERENCES}

Babushok DV, Duke JL, Xie HM, Stanley N, Atienza J, Perdigones N, Nicholas P, Ferriola D, Li Y, Huang H, et al. 2017. Somatic HLA mutations expose the role of class I-mediated autoimmunity in aplastic anemia and its clonal complications. Blood Adv 1: 1900-1910. doi:10.1182/bloodadvances.2017010918

Brown KE, Tisdale J, Barrett AJ, Dunbar CE, Young NS. 1997. Hepatitis-associated aplastic anemia. N Engl J Med 336: 1059-1064. doi:10.1056/NEJM199704103361504

Cartwright T, Perkins ND, L Wilson C. 2016. NFKB1: a suppressor of inflammation, ageing and cancer. FEBS $J$ 283: 1812-1822. doi:10.1111/febs.13627

Chan JK, Bhattacharyya D, Lassen KG, Ruelas D, Greene WC. 2013. Calcium/calcineurin synergizes with prostratin to promote NF-kB dependent activation of latent HIV. PLoS One 8: e77749. doi:10.1371/journal pone.0077749

Chisholm M. 1974. The association between webs, iron and post-cricoid carcinoma. Postgrad Med J 50: 215 219. doi:10.1136/pgmj.50.582.215

Davis EJ, Salem JE, Young A, Green JR, Ferrell PB, Ancell KK, Lebrun-Vignes B, Moslehi JJ, Johnson DB. 2019. Hematologic complications of immune checkpoint inhibitors. Oncologist 24: 584-588. doi:10.1634/theon cologist.2018-0574

de Masson A, Bouaziz JD, Peffault de Latour R, Benhamou Y, Moluçon-Chabrot C, Bay JO, Laquerrière A, Picquenot JM, Michonneau D, Leguy-Seguin V, et al. 2013. Severe aplastic anemia associated with eosinophilic fasciitis: report of 4 cases and review of the literature. Medicine (Baltimore) 92: 69-81. doi:10.1097/ MD.0b013e3182899e78

Dissanayake D, Hall H, Berg-Brown N, Elford AR, Hamilton SR, Murakami K, Deluca LS, Gommerman JL, Ohashi PS. 2011. Nuclear factor-kB1 controls the functional maturation of dendritic cells and prevents the activation of autoreactive T cells. Nat Med 17: 1663-1667. doi:10.1038/nm.2556

Dufour C, Capasso M, Svahn J, Marrone A, Haupt R, Bacigalupo A, Giordani L, Longoni D, Pillon M, Pistorio A, et al. 2004. Homozygosis for (12) CA repeats in the first intron of the human IFN- $\gamma$ gene is significantly associated with the risk of aplastic anaemia in Caucasian population. Br J Haematol 126: 682-685. doi:10 .1111/j.1365-2141.2004.05102.x

Fevang B, Yndestad A, Sandberg WJ, Holm AM, Muller F, Aukrust P, Froland SS. 2007. Low numbers of regulatory $T$ cells in common variable immunodeficiency: association with chronic inflammation in vivo. Clin Exp Immunol 147: 521-525. doi:10.1111/j.1365-2249.2006.03314.x 
Fox AJ, Hiemenz MC, Lieberman DB, Sukhadia S, Li B, Grubb J, Candrea P, Ganapathy K, Zhao J, Roth D, et al. 2016. Next generation sequencing for the detection of actionable mutations in solid and liquid tumors. $J$ Vis Exp. doi:10.3791/52758

Frantz B, Nordby EC, Bren G, Steffan N, Paya CV, Kincaid RL, Tocci MJ, O'Keefe SJ, O'Neill EA. 1994.

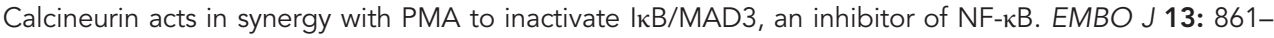
870. doi:10.1002/j.1460-2075.1994.tb06329.x

Gendron N, de Fontbrune FS, Guyard A, Fadlallah J, Chantepie S, D'Aveni M, Le Calloch R, Garnier A, Couturier MA, Morel V, et al. 2020. Aplastic anemia related to thymoma: a survey on behalf of the French reference center of aplastic anemia and a review of the literature. Haematologica 105: e333e336. doi:10.3324/haematol.2019.226134

Genomes Project Consortium, Auton A, Brooks LD, Durbin RM, Garrison EP, Kang HM, Korbel JO, Marchini JL, McCarthy S, McVean GA, et al. 2015. A global reference for human genetic variation. Nature 526: 68-74. doi:10.1038/nature15393

Genovese G, Kahler AK, Handsaker RE, Lindberg J, Rose SA, Bakhoum SF, Chambert K, Mick E, Neale BM, Fromer M, et al. 2014. Clonal hematopoiesis and blood-cancer risk inferred from blood DNA sequence. N Engl J Med 371: 2477-2487. doi:10.1056/NEJMoa1409405

Gerondakis S, Siebenlist U. 2010. Roles of the NF-kB pathway in lymphocyte development and function. Cold Spring Harb Perspect Biol 2: a000182. doi:10.1101/cshperspect.a000182

International Agranulocytosis and Aplastic Anemia Study. 1987. Incidence of aplastic anemia: the relevance of diagnostic criteria. Blood 70: 1718-1721. doi:10.1182/blood.V70.6.1718.1718

Jaiswal S, Fontanillas P, Flannick J, Manning A, Grauman PV, Mar BG, Lindsley RC, Mermel CH, Burtt N, Chavez A, et al. 2014. Age-related clonal hematopoiesis associated with adverse outcomes. N Engl J Med 371: 2488-2498. doi:10.1056/NEJMoa1408617

Jin S, Orabi Al, Le T, Javed TA, Sah S, Eisses JF, Bottino R, Molkentin JD, Husain SZ. 2015. Exposure to radiocontrast agents induces pancreatic inflammation by activation of nuclear factor- $\mathrm{kB}$, calcium signaling, and calcineurin. Gastroenterology 149: 753-764 e711. doi:10.1053/j.gastro.2015.05.004

Kaileh M, Sen R. 2012. NF-кB function in B lymphocytes. Immunol Rev 246: 254-271. doi:10.1111/j.1600065X.2012.01106.x

Karin M, Lin A. 2002. NF-kB at the crossroads of life and death. Nat Immuno/ 3:221-227. doi:10.1038/ni0302-221

Kaustio M, Haapaniemi E, Goos H, Hautala T, Park G, Syrjänen J, Einarsdottir E, Sahu B, Kilpinen S, Rounioja S, et al. 2017. Damaging heterozygous mutations in NFKB1 lead to diverse immunologic phenotypes. $J$ Allergy Clin Immunol 140: 782-796. doi:10.1016/j.jaci.2016.10.054

Kina I, Sultuybek GK, Soydas T, Yenmis G, Biceroglu H, Dirican A, Uzan M, Ulutin T. 2019. Variations in Toll-like receptor and nuclear factor-к B genes and the risk of glioma. Br J Neurosurg 33: 165-170. doi:10.1080/ 02688697.2018 .1540764

Lek M, Karczewski KJ, Minikel EV, Samocha KE, Banks E, Fennell T, O’Donnell-Luria AH, Ware JS, Hill AJ, Cummings BB, et al. 2016. Analysis of protein-coding genetic variation in 60,706 humans. Nature 536: 285-291. doi:10.1038/nature19057

Linaburg T, Davis AR, Frey NV, Khawaja MR, Landsburg DJ, Schuster SJ, Svoboda J, Li Y, Borovskiy Y, Olson TS, et al. 2019. Hodgkin lymphoma patients have an increased incidence of idiopathic acquired aplastic anemia. PLoS One 14: e0215021. doi:10.1371/journal.pone.0215021

Lorenzini T, Fliegauf M, Klammer N, Frede N, Proietti M, Bulashevska A, Camacho-Ordonez N, Varjosalo M, Kinnunen M, de Vries E, et al. 2020. Characterization of the clinical and immunologic phenotype and management of 157 individuals with 56 distinct heterozygous NFKB1 mutations. J Allergy Clin Immunol 146: 901-911. doi:10.1016/j.jaci.2019.11.051

Lougaris V, Patrizi O, Baronio M, Tabellini G, Tampella G, Damiati E, Frede N, van der Meer JWM, Fliegauf M, Grimbacher B, et al. 2017. NFKB1 regulates human NK cell maturation and effector functions. Clin Immunol 175: 99-108. doi:10.1016/j.clim.2016.11.012

Marienfeld R, Neumann M, Chuvpilo S, Escher C, Kneitz B, Avots A, Schimpl A, Serfling E. 1997. Cyclosporin A interferes with the inducible degradation of NF-kB inhibitors, but not with the processing of p105/NF-kB1 in T cells. Eur J Immunol 27: 1601-1609. doi:10.1002/eji.1830270703

Messmann H. 2001. Squamous cell cancer of the oesophagus. Best Pract Res Clin Gastroenterol 15: 249-265. doi:10.1053/bega.2000.0172

Meyer S, Kohler NG, Joly A. 1997. Cyclosporine A is an uncompetitive inhibitor of proteasome activity and prevents NF-kB activation. FEBS Lett 413: 354-358. doi:10.1016/S0014-5793(97)00930-7

Mieczkowski J, Kocyk M, Nauman P, Gabrusiewicz K, Sielska M, Przanowski P, Maleszewska M, Rajan WD Pszczolkowska D, Tykocki T, et al. 2015. Down-regulation of IKK $\beta$ expression in glioma-infiltrating micro$\mathrm{glia} / \mathrm{macrophages}$ is associated with defective inflammatory/immune gene responses in glioblastoma. Oncotarget 6: 33077-33090. doi:10.18632/oncotarget.5310 
Nakao S, Takamatsu H, Chuhjo T, Ueda M, Shiobara S, Matsuda T, Kaneshige T, Mizoguchi H. 1994. Identification of a specific HLA class II haplotype strongly associated with susceptibility to cyclosporine-dependent aplastic anemia. Blood 84: 4257-4261. doi:10.1182/blood.V84.12.4257.bloodjournal84124257

Patuzzo G, Barbieri A, Tinazzi E, Veneri D, Argentino G, Moretta F, Puccetti A, Lunardi C. 2016. Autoimmunity and infection in common variable immunodeficiency (CVID). Autoimmun Rev 15: 877-882. doi:10.1016/j autrev.2016.07.011

Podjasek JC, Abraham RS. 2012. Autoimmune cytopenias in common variable immunodeficiency. Front Immunol 3: 189. doi:10.3389/fimmu.2012.00189

Rajaraman P, Brenner AV, Butler MA, Wang SS, Pfeiffer RM, Ruder AM, Linet MS, Yeager M, Wang Z, Orr N, et al. 2009. Common variation in genes related to innate immunity and risk of adult glioma. Cancer Epidemiol Biomarkers Prev 18: 1651-1658. doi:10.1158/1055-9965.EPI-08-1041

Risitano AM, Maciejewski JP, Green S, Plasilova M, Zeng W, Young NS. 2004. In-vivo dominant immune responses in aplastic anaemia: molecular tracking of putatively pathogenetic T-cell clones by TCR $\beta$-CDR3 sequencing. Lancet 364: 355-364. doi:10.1016/S0140-6736(04)16724-X

Sondka Z, Bamford S, Cole CG, Ward SA, Dunham I, Forbes SA. 2018. The COSMIC Cancer Gene Census: describing genetic dysfunction across all human cancers. Nat Rev Cancer 18: 696-705. doi:10.1038/ s41568-018-0060-1

Steffan NM, Bren GD, Frantz B, Tocci MJ, O'Neill EA, Paya CV. 1995. Regulation of IkB a phosphorylation by PKC- and $\mathrm{Ca}^{2+}$-dependent signal transduction pathways. J Immunol 155: 4685-4691.

Tuijnenburg P, Lango Allen H, Burns SO, Greene D, Jansen MH, Staples E, Stephens J, Carss KJ, Biasci D, Baxendale $\mathrm{H}$, et al. 2018. Loss-of-function nuclear factor kappaB subunit 1 (NFKB1) variants are the most common monogenic cause of common variable immunodeficiency in Europeans. J Allergy Clin Immunol 142: 1285-1296. doi:10.1016/j.jaci.2018.01.039

Vallabhapurapu S, Karin M. 2009. Regulation and function of NF-kB transcription factors in the immune system. Annu Rev Immunol 27: 693-733. doi:10.1146/annurev.immunol.021908.132641

Venkataraman L, Burakoff SJ, Sen R. 1995. FK506 inhibits antigen receptor-mediated induction of c-rel in B and T lymphoid cells. J Exp Med 181: 1091-1099. doi:10.1084/jem.181.3.1091

Wehr C, Gennery AR, Lindemans C, Schulz A, Hoenig M, Marks R, Recher M, Gruhn B, Holbro A, Heijnen I, et al. 2015. Multicenter experience in hematopoietic stem cell transplantation for serious complications of common variable immunodeficiency. J Allergy Clin Immunol 135: 988-997 e986. doi:10.1016/j.jaci 2014.11.029

Wilson DB, Link DC, Mason PJ, Bessler M. 2014. Inherited bone marrow failure syndromes in adolescents and young adults. Ann Med 46: 353-363. doi:10.3109/07853890.2014.915579

Young NS. 2018. Aplastic anemia. N Engl J Med 379: 1643-1656. doi:10.1056/NEJMra1413485

Zaimoku Y, Takamatsu H, Hosomichi K, Ozawa T, Nakagawa N, Imi T, Maruyama H, Katagiri T, Kishi H, Tajima A, et al. 2017. Identification of an HLA class I allele closely involved in the autoantigen presentation in acquired aplastic anemia. Blood 129: 2908-2916. doi:10.1182/blood-2016-11-752378

Zhou Y, Cui C, Ma X, Luo W, Zheng SG, Qiu W. 2020. Nuclear factor kappaB (NF-kB)-mediated inflammation in multiple sclerosis. Front Immunol 11: 391. doi:10.3389/fimmu.2020.00391 


\section{COLD SPRING HARBOR Molecular Case Studies}

\section{Aplastic anemia in a patient with CVID due to NFKB1 haploinsufficiency}

Tammarah Sklarz, Stephanie N. Hurwitz, Natasha L. Stanley, et al.

Cold Spring Harb Mol Case Stud 2020, 6: a005769 originally published online September 24, 2020 Access the most recent version at doi: $10.1101 / \mathrm{mcs} .0005769$
Supplementary http://molecularcasestudies.cshlp.org/content/suppl/2020/11/10/mcs.a005769.D Material C1
References This article cites 46 articles, 11 of which can be accessed free at: http://molecularcasestudies.cshlp.org/content/6/6/a005769.full.html\#ref-list-1
License This article is distributed under the terms of the Creative Commons Attribution-NonCommercial License, which permits reuse and redistribution, except for commercial purposes, provided that the original author and source are credited.
Email Alerting Receive free email alerts when new articles cite this article - sign up in the box at the Service top right corner of the article or click here.

